\title{
PENETAPAN BIAYA PRODUKSI TAYANGAN IKLAN DI MADU TV BIRO BLITAR
}

\author{
Agustyas Retno Hernani ${ }^{1}$, Endah Masrunik ${ }^{2}$ \\ ${ }^{1}$ Fakultas Ekonomi Universitas Islam Balitar , 2 Fakultas ekonomi Universitas Islam balitar, \\ email:1tyasretno824@gmail.com,2endahmasrunik@gmail.com
}

Kata kunci:

Biaya produksi

Iklan

Kualitatif

\section{Keywords:}

Production Cost

Advertisement

Qualitative

Agustyas Retno Hernani \& Endah masrunik, (2020).Penetapan Biaya Produksi Tayangan Iklan Di Madu TV Biro Blitar. Akuntabilitas: Jurnal Ilmiah Ilmu-Ilmu Ekonomi, 13(2), 83-91.

\begin{abstract}
ABSTRAK
Biaya produksi merupakan biaya yang terkandung dalam suatu produk atau jasa, sehingga biaya-biaya yang terjadi harus mampu diidentifikasi dan dihitung secara tepat, agar jumlah biaya produksi yang terjadi benar-benar akurat. Tujuan dari penelitian ini yaitu untuk mengetahui biaya apa saja yang terkandung dalam penetapan biaya produksi atas suatu iklan serta bagaimana cara mengkalkulasinya. Metode yang digunakan yaitu diskriptif kualitatif, dimana data dikumpulkan dengan metode wawancara dan observasi kemudian menarik suatu kesimpulan dari hasil wawancara dan observasi tersebut. Hasil dari penelitian ini menunjukkan bahwa biaya produksi yang terjadi atas suatu iklan ditetapkan oleh kantor biro yang terdiri dari biaya sewa alat dan biaya crew atau gaji (diluar gaji pokok) lalu dikalkulasikan jumlahnya dan ditambah dengan biaya transportasi.
\end{abstract}

\section{ABSTRACT}

Production costs are costs contained in a product or service, so the costs incurred must be able to be identified and calculated correctly, so that the total production costs incurred are truly accurate. The purpose of this study is to find out what costs are contained in the determination of production costs for an advertisement and how to calculate them. The method used is descriptive qualitative, where data is collected by interview and observation method and then draws a conclusion from the results of these interviews and observations. The results of this study indicate that the production costs incurred for an advertisement are determined by the bureau which consists of equipment rental costs and crew costs or salaries (excluding basic salaries) then the amount is calculated and added with transportation costs

\section{PENDAHULUAN}

Informasi merupakan salah satu hal yang sangat dibutuhkan dalam menjalankan roda kehidupan. Singkatnya, tanpa informasi tentu kita tidak memiliki

\footnotetext{
Penetapan Biaya Produksi Tayangan Iklan Di Madu TV Biro Blitar

https://doi.org/10.35457/xxx

(c) 2019 Akuntabilitas: Jurnal Ilmu-Ilmu Ekonomi. Semua hak cipta dilindungi undang-undang
} 
pandangan dalam rangka mengambil suatu keputusan yang bijak untuk bertindak. Informasi yang dimaksud disini sangat kompleks, baik informasi mengenai perkembangan ekonomi, politik maupun sosial budaya. Dewasa ini perkembangan informasi terjadi dengan sangat cepat, setiap detiknya informasi dapat berubah-ubah dan mengakibatkan begitu banyak berita bohong yang beredar di masyarakat. Salah satu alat penyuguh informasi yang minim berita bohong yaitu televisi, dilain itu tentu ada banyak sekali media seperti televise, radio, koran atau majalah.

Televisi merupakan salah satu hasil kemajuan teknologi di bidang informasi, didalamnya terdapat berbagai stasiun televisi yang merupakan perusahaan jasa dan kini telah banyak berdiri di Indonesai. Setelah berhasil menarik perhatian masyarakat, kini keberadaannya mulai tergeser oleh media terbaru yaitu smartphone. Meskipun keeksisan layar kaca mulai menurun, namun bukan berarti para creator stasiun televisi tumbang semangatnya, hal tersebut dibuktikan dengan makin merebaknya stasiun televisi lokal di Indonesia. Berbagai tayangan seperti hiburan berupa sinetron, konser, tayangan religi, olah raga, budaya serta tentunya berita terkini disuguhkan secara apik oleh para crew tidak lain agar stasiun televisi dapat terus bersaing baik dengan sesamanya maupun dengan pesaing lainnya.

Selanjutnya, salah satu sumber dana stasiun televisi adalah iklan. Kegiatan memasarkan suatu produk merupakan hal vital dalam sebuah perusahaan juga dengan sektor perekonomian baik makro maupun mikro. Iklan merupakan suatu proses memperkenalkan barang atau jasa melalui suatu media agar publik tertarik dan mau membeli serta menggunakan barang yang diiklankan (Nirmawan, 2013). Melalui iklan suatu barang atau jasa harus memberikan citra positif bagi konsumen sebab barang dan jasa tersebut dituntut untuk dapat bersaing dengan sesamanya. Maka dari itu, melihat betapa pentingnya peran iklan dalam hal pemasaran produk, suatu perusahaan harus mencari media penyalur informasi yang strategis agar dapat berdampak secara maksimal dalam hal penjualan mereka.

Tanpa disadari iklan merupakan hal yang sangat unik, terkadang iklan yang tayang di stasiun televisi dapat melekat di kepala kita namun terkadang juga berlalu begitu saja. Iklan yang dikemas secara menarik dan singkat akan sangat berbeda dampaknya dengan iklan yang sengaja disusun sangat panjang dengan harapan 
banyak informasi yang diserap oleh masyarakat padahal pada kenyataannya masyarakat malah dengan sengaja mengganti saluran untuk melewatkan iklan tersebut. Hal tersebut bukan berarti iklan yang lebih panjang malah lebih buruk, namun dalam hal penyampain secara visual harus lebih diperhatikan. Iklan merupakan sebuah bentuk informasi produk maupun jasa dari produsen kepada konsumen maupun penyampaian pesan dari sponsor melalui suatu media (Lukitaningsih, 2013) .Tanpa iklan mustahil suatu produk dapat dikenal oleh masyarakat, maka dari itu selain melalui media yang berada di smartphone, media melalui layar kaca masih sangat strategis dalam pemasaran. Dalam hal ini, tentu stasiun televisi menuntut imbal balik dari pemasangan iklan yang telah dilakukannya berupa tarif.

Hampir seluruh bidang kehidupan membutuhkan sebuah sistem perhitungan. Tentu kita sadari bahwa ilmu akuntansi berkaitan erat dengan keuangan yang mana tidak ada dalam satu organisasipun yang luput dari alur keuangan. Bukan hanya badan usaha berupa bank, koperasi atau pengkreditan saja yang kental dengan pemanfaatan ilmu akuntansi. Dalam penerapannya, penentuan tarif iklan tidak terlepas dari adanya sistem perhitungan akuntansi. Akuntansi sendiri adalah proses pengidentifikasian, pengesahan, pengukuran, pengakuan, pengklarifikasian, penggabungan, peringkasan, dan penyajian data keuangan dasar (bahan oleh akuntansi) yang terjadi darin kejadian-kejadian, transaksi-transaksi atau kegiatan operasi suatu unit organisasi dengan cara tertentu untuk menghasilkan informasi yang relevan bagi pihak yang berkepentingan (Suwardjono, 2015:10) Sedangkan akuntansi biaya adalah proses pencatatan, penggolongan, peringkasan dan penyajian biaya pembuatan dan penjualan produk atau jasa dengan cara-cara tertentu serta penafsiran terhadapnya (Mulyadi, 2010)

Sementara itu, untuk menarik minat calon pemasang iklan, pemasangan tarif produksi iklan tidak boleh terlalu tinggi, mengingat begitu banyak televisi lokal yang telah berkembang di Indonesai. Memanfaatkan sumber daya manusia sesedikit dan seefektif mungkin namun dengan kerja yang professional sehingga menghasilkan produk yang unggul merupakan hal yang harus ditekankan guna meminimalisir dana yang digunakan. Program pada stasiun televisi sendiri juga

Penetapan Biaya produksi Tayangan Iklan Di Madu TV Biro Blitar 
berpengaruh besar, pasalnya kesesuaian acara dengan iklan yang ditayangkan harus selaras, hal ini dilakukan agar pemasangan iklan dapat sesuai dengan target pasar barang atau jasa yang diiklankan. Trik-trik pemasaran sendiri harus diterapkan secara cerdik dan sesuai porsinya agar tidak merugikan stasiun televisi itu sendiri seperti pemberian diskon atau penambahan jadwal tayang jika pemasang iklan mau bekerjasama dengan jangka waktu tertentu.

Penetapan tarif produksi dilakukan agar pada saat memproduksi tayangan pihak televisi tidak rugi dan dapat memperkirakan keuntungan yang didapatkan. Pada badan usaha yang berorientasi pada laba dengan keluaran berupa jasa sangat sulit untuk menentukan nilai harga dari jasa kita, hal tersebut berbeda dengan keluaran berupa barang. Pada produksi tersebut yang dinilai bukan hanya tentang bentuk dari iklan yang dapat dilihat di televisi namun juga seberapa berhasilkah pengiklanan tersebut untuk memperkenalkan sebuah produk ke pasar. Badan usaha jasa dituntut untuk memenuhi ekspektasi dari pengguna jasa. Hal inilah yang membuat penetapan tarif sedikit kesulitan.

Kegiatan meramalkan seberapa besar pengaruh jasa iklan terhadap konsumen yang tidak pasti inilah yang menciptakan dilema dalam penentuan harga. Apabila tarif dipasang rendah tentu laba yang didapat akan sangat minim atau bahkan tidak mendapat laba sama sekali namun apabila tarif dipasang dengan harga yang tinggi maka media tersebut akan kalah saing dipasarnya. Tidak jarang pihak televisi melakukan follow up kepada pengguna jasa untuk memastikan dampak dari pemasangan iklan tersebut. Hal yang sering ditawarkan adalah dengan mengganti jam tayang iklan yang belum memberikan kepuasan bagi pelanggan.

\section{METODE PENELITIAN}

Metode penelitian dalam penelitin ini yaitu metode diskriptif kualitatif merupakan suatu metode penelitian yang memberikan suatu penjelasan atau ulasan secara rinci dari data yang diperoleh melalui wawancara (Sugiyono, 2018), kepada subjek atau pihak yang terlibat dalam penelitian yaitu manajer marketing dan kepala biro Madu TV Blitar

\section{PEMBAHASAN}


Biaya produksi adalah satuan moneter yang dikeluarkan dalam rangka memproduksi barang atau jasa. Biaya produksi disini ditetapkan oleh biro dan dibebankan kepada pemasang iklan diluar tarif iklan dan pajak produksi. Sedangkan untuk biaya terhadap crew merupakan biaya jasa bonus diluar gaji pokok. Diantara proses penetapan biaya produksi diantaranya :

a. Menentukan Iklan yang Diinginkan

Jasa iklan yang disediakan Madu TV sangat beragam jenisnya sesuai dengan yang telah di jelaskan pada sub bab sebelumnya. Keberagaman jenis iklan ini tentu akan mempengaruhi jenis dan banyaknya alat yang digunakan serta banyaknya crew yang terlibat yang tentu akan mempengaruhi harga produksi tayangan iklan tersebut. Dalam hal ini klien dapat dengan bebas memilih sesuai dengan budget yang dimiliki dengan bantuan arahan oleh marketing dari stasiun televisi.

b. Menentukan Konsep Terkait Iklan

Konsep merupakan gambaran bagaimana iklan akan diambil. Tingkat kesulitan dalam rangka produksi akan mempengaruhi biaya produksi iklan itu sendiri. Apabila tingkat kesulitan tinggi tentu akan menyebabkan lebih banyak tenaga dan pikiran serta jumlah crew yang dilibatkan didalamnya.

Penentuan konsep iklan akan sangat berpengaruh terhadap minat masyarakat dalam menyaksikan iklan tersebut. Apabila minat masyarakat tinggi maka maksud dan tujuan ditayangkannya iklan tersebut akan tercapai. Iklan harus dikemas dengan menarik dengan diskusi antara pihak televisi dengan sponsor agar hasilnya maksimal.

c. Penentuan Biaya Produksi 
Biaya produksi merupakan biaya yang digunakan oleh produsen dalam rangka menghasilkan suatu produk dengan nilai jual. Biaya produksi merupakan hal yang sangat vital guna menentukan harga jual suatu produk sehingga dalam perinciannya diperlukan kehati-hatian yang ekstra sebab dapat mempengaruhi profit dan laba suatu perusahaan. Penetapan biaya produksi di Madu TV Biro Blitar di tentukan atau berdasarkan ketetapan dari kantor biro dan sangat memperhatikan harga pasaran yang mengacu pada harga produksi di Production House, hal ini berbeda dengan penelitian (Meiristia et al., (2017) dimana pembebanan biaya produksi dan penentuan harga jual ditentukan oleh kantor pusat. Berikut merupakan rincian biaya produksi pada masing-masing iklan di Madu TV Biro Blitar:

1. Running Text

Iklan running text hanya berisi 250 hingga 500 karakter dan mengingat biaya produksi pada Madu TV Biro Blitar merupakan pendapatan bonus dengan pertimbangan tindakan yang dilakukan oleh crew sangat minim serta tidak memerlukan adanya turun lapangan maka biaya produksi digratiskan sehingga pemasang iklan hanya perlu membayar biaya iklan. Berbeda dengan penelitian Oktafiah, (2010) dimana pada iklan running text di Jtv membebankan atau menetapkan biaya iklan sebesar 30\% dari harga TVC 30".

2. TVC dan Blocking time

Pada iklan TVC dan blocking time terdapat beberapa crew yang terlibat didalamnya serta dalam beberapa proyek pemasangan iklan diperlukan adanya turun ke lapangan oleh para crew. Crew yang terlibat 
dalam produksi iklan TVC dan blocking time yaitu presenter jika dibutuhkan, kamerawan serta editor dengan biaya produksi sebagai berikut :

Tabel 4.1 Biaya Produksi Iklan TVC dan Blocking Time

\begin{tabular}{llccclll}
\hline No & $\begin{array}{c}\text { Komponen } \\
\text { Biaya }\end{array}$ & Banyaknya & Harga Satuan & \multicolumn{2}{c}{ Jumlah } \\
\hline $\mathbf{1}$ & Kamera & 2 & Rp. & 250.000 & Rp. & 500.000 \\
$\mathbf{2}$ & Kamerawan & 2 & Rp. & 100.000 & Rp. & 200.000 \\
$\mathbf{3}$ & Presenter & 1 & Rp. & 50.000 & Rp. & 50.000 \\
$\mathbf{4}$ & Editor & 1 & Rp. & 100.000 & Rp. & 100.000 \\
& 5 & Transportasi & & & & Rp. & 50.000 \\
\hline
\end{tabular}

Sumber : Madu TV Biro Blitar

3. Talkshows

Talk Show biasanya hanya membutuhkan kamerawan saja sebab biasanya SDM yang berada di depan layar sudah disiapkan oleh pemasang iklan, sehingga biaya produksi hanya mencangkup 2 hingga 3 kamera dengan masing-masing biaya Rp. 250.000, begitu juga total kamerawan yang dilibatkan disesuaikan dengan kamera yang dioperasikan dengan biaya masing-masing sebesar Rp. 100.000 serta biaya transport apabila lokasi berada di luar kantor sebesar Rp.50.000. Apabila akumulasikan maka keseluruhan biaya produksi sebesar Rp. 700.000 hingga Rp. 1.100.000.

4. Event 
Pada iklan berupa event, crew yang terlibat hamper sama dengan

iklan TVC, perbedaanya hanya pada jumlah kamera serta kamerawan yang ikut terlibat yaitu 2 hingga 4 kamera dan kamerawan. Apabila akumulasikan maka keseluruhan biaya produksi sebesar Rp. 900.000 hingga Rp. 1.600.000.

Tabel 4.2 Biaya Produksi Iklan Event

\begin{tabular}{|c|c|c|c|c|}
\hline No & $\begin{array}{l}\text { Komponen } \\
\text { Biaya }\end{array}$ & Banyaknya & $\begin{array}{l}\text { Harga } \\
\text { Satuan }\end{array}$ & Jumlah \\
\hline 1 & Kamera & $2-4$ & Rp. $\quad 250.000$ & $\begin{array}{lc}\text { Rp. } & 500.000 \\
& \text { hingga } \\
\text { Rp. } & 1.000000\end{array}$ \\
\hline 2 & Kamerawan & $2-4$ & Rp. 100.000 & $\begin{array}{ll}\text { Rp. } & 200.000 \\
& \text { hingga } \\
\text { Rp. } & 400.000\end{array}$ \\
\hline No & $\begin{array}{c}\text { Komponen } \\
\text { Biaya }\end{array}$ & Banyaknya & $\begin{array}{l}\text { Harga } \\
\text { Satuan }\end{array}$ & Jumlah \\
\hline 3 & Presenter & 1 & Rp. $\quad 50.000$ & 50.000 \\
\hline 4 & Editor & 1 & Rp. 100.000 & 100.000 \\
\hline 5 & Transportasi & & & 50.000 \\
\hline
\end{tabular}

Sumber : Madu TV Biro Blitar

5. Warta Khusus dan Kolom Bisnis

Keseluruhan iklan berada di bawah divisi program terkecuali warta khusus dan kolom bisnis yang berada di bawah divisi news. Kedua jenis iklan ini akan ditayangkan dalam bentuk berita sehingga tidak membutuhkan biaya produksi dan cukup membayar biaya iklan saja. 


\section{KESIMPULAN}

Berdasarkan uraian yang bersumber dari data yang didapatkan penulis selama melakukan penelitian di Madu TV Biro Blitar dapat ditarik kesimpulan bahwa terdapat banyak sekali jenis iklan yang ditawarkan dengan beragam komponen dan harga yaitu running text, TVC, talk show, blocking time, even, warta khusus serta kolom bisnis.

Dalam kegiatan penayangan suatu iklan pada Madu TV, penetapan tarif iklan merupakan kebijakan dari kantor pusat yang didalamnya belum termasuk biaya produksi, sehingga kantor biro membuat suatu kebijakan dengan menambahkan komponen-komponen biaya produksi yang belum ditetapkan oleh kantor pusat, serta menyesuaikan dengan jenis iklan karena biaya produksi antar iklan tidak sama yang dipengaruhi oleh beberapa aspek, diantaranya jenis iklan yang diinginkan serta crew dan alat yang terlibat didalamnya. Biaya produksi yang didapatkan oleh biro akan dialokasikan kepada SDM yang terlibat dalam proses pembuatan diluar gaji pokok dari perusahaan serta komponen-komponen lain yang terlibat dalam proses produksi seperti alat dan biaya transportasi.

\section{DAFTAR PUSTAKA}

Lukitaningsih, A. (2013). IKLAN YANG EFEKTIF SEBAGAI STRATEGI KOMUNIKASI PEMASARAN Ambar Lukitaningsih Fakultas Ekonomi Universitas Sarjanawiyata Tamansiswa Yogyakarta. Jurnal Ekonomi Dan Kewirausahaan, 13(2), 116-129. http://ejurnal.unisri.ac.id/index.php/Ekonomi/article/view/670/576

Meiristia, S., Fahrizal, A., Sariningsih, E., \& Belakang, L. (2017). Analisis Penetapan Biaya Produksi Dan Penentuan Harga Jual Iklan Pada PT Radio Suara Tiara Indah. 6(1), 47-55.

Mulyadi. (2010). Akuntansi biaya (5th ed.). UPP STIM YKPN.

Nirmawan, T. M. (2013). Rahmawati, Ambar Aulia. 2012. “Strategi Penetapan Tarif Iklan pada PT. Joglo SemarPrima Media". Fakultas Ekonomi. Universitas Sebelas Maret. Skripsi.

Oktafiah, T. (2010). STUDI ANALISIS HUKUM ISLAM TERHADAP PENETAPAN T ARIF IKL,AN DI TELEVISI (Studi Kasus fada Divisi Periklanan JTV Surabaya). Skripsi.

Sugiyono. (2018). Metode Penelitian Kombinasi (mixed Methods). In Alfabet.

Suwardjono. (2015). Teori akuntansi perekayasaan laporan keuangan, Edisi 3. BPFE. 